\title{
O pacto narcísico da casa-grande: a representação das mulheres negras a partir de Lélia Gonzalez e Gilberto Freyre
}

Marina de Oliveira Reis

\section{Resumo}

A partir da obra Casa-grande \& senzala, de Gilberto Freyre, este artigo investiga a construção de mitos e estereótipos relacionados à representação das mulheres negras no período colonial. Resgatando o pensamento de Lélia Gonzalez, busca-se demonstrar que essa representação distorcida é constantemente atualizada, de modo a reservar um lugar social de silenciamento, objetificação e violência para as mulheres negras.

Palavras-chave: Racismo - Sexismo - Colonial - Mulheres Negras - Imagens controladoras. 


\section{Introdução}

Neste artigo pretendo promover uma reflexão sobre a representação das mulheres negras, investigando a historicidade e a atualidade de certos estereótipos. Para isso, inicio minha análise resgatando a contribuição da socióloga feminista Patricia Hill Collins (2000), que pensa o lugar das mulheres negras a partir da categoria de imagens controladoras. Segundo a autora, o modus operandi dessas imagens se dá pela criação de uma série de estereótipos sobre determinado grupo, fomentando representações negativas que objetificam e desumanizam esses sujeitos, o que justificaria, assim, seu controle social.

A maioria das imagens controladoras direcionadas a nós, mulheres negras, é forjada como resultante da interseção entre racismo, sexismo e colonialidade, alimentando uma dinâmica cruel que não só nos mantêm na base da pirâmide social (MARCONDES, 20I3) como também afeta nossa própria subjetividade, na medida em que nossa imagem é socialmente construída de forma distorcida, baseando-se em mitos e estereótipos.

Mais especificamente, pretendo investigar a representação das mulheres negras na obra Casa-grande \& senzala, de Gilberto Freyre. Nesse livro, lançado em I933, o autor promove uma ruptura com a forma em que as relações raciais eram trabalhadas até então, rompendo com o darwinismo social, corrente amplamente reconhecida na época, que pretendia explicar as relações sociais por uma abordagem biologizante. Os principais pensadores daquele momento transplantavam da Biologia as teorias da evolução e seleção natural, aplicando-as nas interações humanas. Assim, características sociais e biológicas determinariam a superioridade de um grupo em relação a outro, em que o padrão europeu era estabelecido como parâmetro de sociedade apta e ideal.

Como essa breve síntese do livro evidencia, embora seja bem verdade que o principal objetivo de Freyre não era refletir sobre raça e gênero, sua obra abre possíveis caminhos para pensarmos essas categorias, uma vez que descreve a imagem da mulher negra construída no período colonial.

Como contraste, procuro situar a obra de Freyre pontuando algumas impropriedades de suas interpretações, baseando-me no pensamento de Lélia Gonzalez, que demonstra como esses mitos são atualizados e propiciam a descarga de altas doses de violência sobre corpos negros. Concluo, portanto, que esses mitos funcionam como verdadeiras imagens controladoras, a fim de manter esse status de subalternidade que nos é reservado desde o período colonial. 


\section{Mulheres negras: situando a academia}

Em meados do século passado, a intelectualidade brasileira foi tomada pelo desafio de produzir obras que refletissem sobre nossa formação cultural, social e racial. Nesse contexto, Gilberto Freyre, Caio Prado Júnior e Sérgio Buarque de Holanda ganham destaque, pois, a partir de perspectivas distintas, produziram obras obrigatórias para compreendermos nosso lugar enquanto nação, sendo até hoje reconhecidos pela academia como "intérpretes" do Brasil.

Forjar um ideal de nação por meio da escrita é um privilégio conferido a determinados grupos sociais e, assim, as interpretações de Brasil timbradas como válidas partem de uma visão de mundo masculina e branca. Por muito tempo essa foi a única perspectiva epistemológica reconhecida pela academia, já que o racismo provoca um verdadeiro "epistemicídio" de intelectos negros, enquanto o sexismo desqualifica o pensamento de mulheres.

Há, portanto, o não lugar de negros, em geral, e de mulheres negras, em particular, na produção de conhecimento nas ciências humanas. Assim, muitas das questões históricas que nos dizem respeito não são enfrentadas pela narrativa oficial, já que as experiências dos seus narradores não acessam a especificidade dos sujeitos marcados pelas opressões de raça, classe e gênero. Ou pior: mesmo quando alguma reflexão é produzida sobre nós, não raras vezes a perspectiva é de objetivação de nossos corpos e romantização das violências perpetradas sobre eles. O papel das mulheres negras nunca é narrado a partir de uma lente que considera a articulação política e a resistência histórica desempenhada por esse grupo, sempre narrado a partir da ótica da passividade.

É necessário, portanto, recontar nossa história. Neste trabalho, em virtude do limitado número de páginas, decidi apenas pontuar alguns aspectos problemáticos da narrativa hegemônica, apresentando a contribuição de intelectuais negras sobre o mesmo tema. Em outras palavras, minha proposta não pretende inutilizar as contribuições desses autores "oficiais", mas apreender as leituras que verdadeiramente avançaram no estudo das relações raciais, bem como apontar possíveis insuficiências e visibilizar a obra de mulheres negras que também estão refletindo sobre esse mesmo período histórico. Nesse sentido, leio a contribuição de intelectuais como Lélia Gonzalez, Sueli Carneiro e Jurema Werneck como reinterpretações do Brasil, pois redimensionam questões que ficaram ocultas da lente clássica, construindo uma outra narrativa que enfrenta a colonialidade e as suas implicações para as dinâmicas de raça e gênero no Brasil.

A fim de compreender a constante do sexismo e do racismo na formação cultural brasileira, a filósofa e historiadora Lélia Gonzalez (I984) oferece uma leitura da formação cultural do país que adota a psicanálise como lente de inves- 
tigação. Nesse contexto, trazendo as categorias trabalhadas por Freud e Lacan, a autora evidencia que se situarmos as mulheres negras na dialética travada entre consciente inconsciente (memória), veremos que a consciência social aplica uma força de apagamento a certos papéis que elas historicamente assumiram. Porém, esse apagamento não se realiza por completo, sendo mero "recalque", visto que o inconsciente os mantém vivos. Assim, a maneira através da qual as mulheres negras são vistas, definirá qual papel representará em determinado contexto, que estão centrados nas noções de mãe preta, mulata e empregada doméstica. Analiso, nas duas seções posteriores, cada um destes papéis detalhadamente.

\section{Mito da mãe preta}

Casa-grande \& senzala (FREYRE, 2005) evidencia a existência de vários tipos de trabalho escravo: havia o escravo da senzala, que trabalhava na lavoura, e o da casa-grande, que desenvolvia os serviços domésticos nesse ambiente. $\mathrm{O}$ autor descreve um cenário no qual não só o trabalho é diferente, mas o tratamento dispensado também é outro. Segundo essa narrativa, a relação do senhor com os escravos domésticos seria marcada pela docilidade e até por uma certa dose de afeto, na medida em que estes frequentariam o núcleo familiar da casa-grande, como podemos observar a seguir:

A casa-grande fazia subir da senzala para o serviço mais íntimo e delicado dos senhores uma série de indivíduos - amas de criar, mucamas, irmãos de criação dos meninos brancos. Indivíduos cujo lugar na família ficava sendo não o de escravos mas o de pessoas de casa. [...] Quanto às mães pretas, referem as tradições o lugar verdadeiramente de honra que ficavam ocupando no seio das famílias patriarcais. Alforriadas, arredondavam-se quase sempre em pretalhonas enormes. Negras a quem se faziam todas as vontades: os meninos tomavam-lhe a benção; os escravos tratavam-nas de senhoras; os boleeiros andavam com elas de carro. Em dia de festa, quem as visse anchas e engajentas entre os brancos da casa, havia de supô-las senhoras bem-nascidas; nunca ex-escravas vindas da senzala (FREYRE, 2005, p. 435, grifo nosso).

Nesse sentido, a mãe preta é o símbolo dessa dinâmica social apresentada por Freyre. É, normalmente, a escrava mais velha, que trabalha nos afazeres domésticos e cuida de todos com carinho e dedicação, como se fossem filhos. No imaginário da casa-grande, "esta figura simpática, amorosa e inofensiva realiza a aceitação sem resistência do poder instituído, da escravidão" (CARDOSO, 20I4, p. 976). 
Lélia Gonzalez problematiza esse lugar de subserviência que a narrativa oficial conferiu à mãe preta, criticando a construção Freyriana explicitada aqui. $\mathrm{Na}$ verdade, sua atuação estava imbricada de resistência, e não de passividade. Passividade seria aceitar, sem objeção, a imposição da família patriarcal, mas o que fez foi justamente o contrário: soube utilizar de forma potente o interior da casa-grande, trazendo para o núcleo familiar do colonizador as tradições africanas, numa postura que, conscientemente ou não, demonstra-se totalmente subversiva (GONZALEZ apud BAIRROS, 2006). Assim, a partir do que era possível, atuou no sentido anti-horário da árvore do esquecimento ${ }^{\mathrm{I}}$, garantindo a sobrevivência do seu próprio ser e mantendo vivas suas tradições, culturas, língua etc.

Essa forma de resistência afetou de forma indelével o processo de formação cultural brasileiro, que não mais poderia reivindicar somente referenciais europeus. O Brasil já estaria africanizado - a começar pela linguagem, posto que o português brasileiro sofreu influência direta das línguas africanas e indígenas e, desse modo, o mais correto seria definirmos nosso idioma como "pretuguês" (GONZALEZ, I988, p. 70).

A narração do papel da mãe preta apenas sob o prisma da ética do cuidado, abnegando toda sua resistência e agenciamento histórico, perpetua-se e acaba por desenhar um estereótipo a ser carregado pelas mulheres negras. Assim, o imaginário é constantemente atualizado e, ainda hoje, "a mãe preta representa o esperado da mulher negra pela sociedade branca e de classe média: resignação, passividade diante das situações de violência e opressão" (GARDOSO, 20I4, p. 976). Nesse sentido, as mulheres negras são consideradas "naturalmente" mais cuidadosas, devendo sempre se dedicar às necessidades dos outros - especialmente dos mais poderosos (CARNEIRO, 2006) -, sendo sua existência como indivíduo e sujeito político completamente apagada.

\section{Mito da mulata}

Em um sistema econômico que hierarquiza seres humanos nas categorias de "senhor" e "escravo", não só a produção econômica da sociedade é afetada: a

I Conta-se que os negros capturados na África, antes de embarcarem nos navios negreiros, eram obrigados a dar diversas voltas em torno da árvore sagrada, devendo depositar, ali, sua religiosidade, identidade e história para, em seguida, serem batizados, adquirindo uma identidade cristã ocidental. Essa árvore sagrada era o Baobá, que ficou conhecida como "árvore do esquecimento", já que simbolizava a perda da memória e da subjetividade do africano escravizado. Dar a volta em sentido anti-horário na árvore do esquecimento, portanto, significa desfazer simbolicamente essa violência, reafirmando seu próprio "eu". 
própria construção subjetiva dos "senhores" também é moldada nesses termos - senhores estes que se entendem no direito de subjugar, inclusive sexualmente, suas/seus escravas/os.

A forma encontrada por Casa-grande \& senzala para justificar toda a sorte de violência sexual foi a atribuição, no plano discursivo, de uma erotização exacerbada ao corpo negro, como se essa fosse uma característica própria da raça. Assim, a narrativa das sociedades escravocratas descreviam os negros como hipersexualizados, sendo o elemento depravador e corruptor da sexualidade da família colonial (FREYRE, 2005).

Nesse sentido, os relatos de viajantes que transitavam por sociedades escravocratas indicavam que, nos locais marcados pela presença negra na condição de escravo, como nos Estados Unidos e no Brasil, os homens iniciavam sua vida sexual mais cedo (FREYRE, 2005). Esses dados, porém, foram apropriados e interpretados de forma a culpabilizar a negra e mulata pela sua suposta erotização exacerbada, sem denunciar que a própria educação dos senhores de engenho era no sentido da demonstração de virilidade por meio do abuso sexual, como Gilberto Freyre demonstra a seguir:

Não eram as negras que iam esfregar-se pelas pernas dos adolescentes louros, estes é que, no sul dos Estados Unidos, como nos engenhos de cana do Brasil, os filhos dos senhores, criavam-se desde pequenos para garanhões, ao mesmo tempo que as negras e mulatas para "ventres geradores" [...] É verdade que lá como aqui não faltou quem, confundindo resultado e causa, responsabilizasse a negra e seus "strong sex instincts" e principalmente a mulata - "the lascivious hybrid woman" - pela depravação dos rapazes brancos. Entre nós, já vimos que Nina Rodrigues considerou a mulata um tipo anormal de superexcitada sexual [...] Nós, uns inocentinhos: elas, uns diabos, dissolvendo-nos a moral e corrompendo-nos o corpo (FREYRE, 2005, p. 46I, grifo nosso).

A sexualização como característica biológica dos negros foi difundida de tal forma que, ainda hoje, os corpos negros são marcados por essa constante representação. Aqui, retomo o pensamento de Lélia Gonzalez (I984), na medida em que a autora reflete sobre como a hipersexualização das mulheres negras por vezes é esquecida e apagada da história, enquanto, em outros momentos, é amplamente fomentada.

Segundo a autora, atualmente a mulher negra apresenta uma dupla imagem: mulata e empregada doméstica. Na figura da mulata, no entre parênteses do Carnaval, a mulher negra é hipersexualizada, e seu corpo, desejado. Passado esse momento festivo, todo esse desejo acumulado pelo corpo negro vai 
se descarregar sob a forma de violência, justamente na figura da empregada doméstica.

Gonzalez demonstra que essas imagens são opostas e contemplam duas reformulações dadas ao papel da mucama no período colonial. Segundo o dicionário Aurélio, a palavra "mucama" significa "a escrava negra moça e de estimação que era escolhida para auxiliar nos serviços caseiros ou acompanhar pessoas da família” (FERREIRA, 2009). Essa palavra, porém, é proveniente da língua quimbunda, e se nos direcionarmos à etimologia, veremos que "mukama" significa "concubina, escrava que era amante do seu senhor" (BAIRROS, 2006, p. 55).

Dessa forma, vemos que a interpretação trazida pelo dicionário denota apenas a dimensão do serviço doméstico, apagando o fato de que as mucamas também eram exploradas sexualmente por seus senhores, questão que a etimologia da palavra traz à tona. A narrativa oficial, portanto, reflete a dimensão da consciência, uma vez que pretende apagar o registro da função sexual da mucama, que o inconsciente mantém vivo - dinâmica que podemos perceber justamente no Carnaval (GONZALEZ, I984).

A figura de mulata ou empregada doméstica emergirá a depender do contexto em que somos vistas. A mulata é a representação da mulher negra no Carnaval: é a rainha da avenida, cobiçada, desejada e erotizada, ou seja, a "mukama" que deve ser objeto sexual. Fora desse espaço festivo permitido, essa mulher negra outrora desejada se transfigura na empregada doméstica, ou seja, a "mucama" do dicionário oficial, que é "o burro de carga que carrega sua família e a dos outros nas costas. Daí ela ser o lado oposto da exaltação; porque está no cotidiano. E é nesse cotidiano que podemos constatar que somos vistas como domésticas" (GONZALEZ, I984, p. 230).

Como fica evidente, a herança colonial racista e sexista ainda projeta nas mulheres negras todos os mitos criados pelo colonizador branco, o que faz que nossos corpos ainda sejam objetificados, hipersexualizados e ceifados de várias formas. E isso se evidencia, inclusive, nas estatísticas criminais, em que as mulheres negras constantemente figuram entre as principais vítimas de estupro e mortes violentas no país².

2 As mulheres negras têm mais chance de serem alvo de violência no Rio de Janeiro, como constata pesquisa divulgada pelo Instituto de Segurança Pública (ISP) (TEIXEIRA; PINTO; MORAES, 2OIO). O Dossiê Mulher 2010 mostra que as mulheres pretas e pardas são a maioria entre as vítimas de homicídio doloso $(55,2 \%)$, tentativa de homicídio ( $5 \mathrm{I} \%$ ) e lesão corporal $(52, \mathrm{I} \%$ ), além de estupro e atentado violento ao pudor ( $54 \%)$. As mulheres brancas só são maioria nos crimes de ameaça (50,2\%). 


\section{v. Conclusão: o pacto narcísico}

A imagem das mulheres negras é historicamente construída a partir da objetificação, sexualização e negação de seu papel enquanto sujeito político.

Nessas linha finais, recorro ao conceito de "pacto narcísico" utilizado por Maria Aparecida da Silva Bento (2002) como chave de análise, a fim de compreender o que possibilita a manutenção dessa representação negativa na atualidade. Segundo a mitologia grega, Narciso era um jovem dotado de uma beleza singular. O rapaz atraía a paixão de muitas ninfas, mas, por ser muito vaidoso e egoísta, só conseguia amar a si mesmo. Em uma oportunidade, ao ver sua própria imagem refletida em um lago, apaixonou-se por ela e permaneceu contemplando-a ininterruptamente, o que o paralisou, levando-o a definhar até a morte.

Nesse sentido, creio que, assim como Narciso, a casa-grande adotou uma sobrevalorização de si, nutrindo um amor exacerbado por sua própria imagem e, consequentemente, depreciando a imagem de outros sujeitos e pactuando um lugar de subalternidade para corpos negros no período colonial.

A dimensão de casa-grande, neste texto, foi descrita em muitos sentidos. A despeito da casa-grande enquanto ambiente habitado pelo senhor de escravos e sua família ter perdido sentido desde a abolição da escravatura, a casa-grande enquanto lugar social que dá acesso a determinados privilégios ainda permanece concretamente. E, assim, entendo que os grupos dominantes, a fim de conservarem seus privilégios, inconscientemente, (re)pactuam a manutenção de imagens controladoras, e, por isso, essa construção estereotipada desenhada no período colonial permanece, até hoje, intocada.

$\mathrm{Se}$, na diáspora africana, as mulheres negras tinham coragem para lutar contra a desumanização que a própria escravidão pressupunha, ainda hoje precisamos denunciar o confisco da nossa palavra, que pretende, assim, manter na cifra oculta toda a objetificação, todo o estupro, o encarceramento, o genocídio. No entanto, enquanto há todo um trabalho de construção da representação da mulher negra fundada em mitos e estereótipos, também há intelectuais - principalmente mulheres negras - desenvolvendo um hercúleo trabalho no sentido de construir uma outra narrativa possível, registrando nossa (re)existência que a história oficial e os privilégios fazem questão de apagar.

\section{Referências}

BAIRROS, L. Lembrando Lélia Gonzalez. In: WERNECK, J.; MENDONÇA, M.; WHITE, E. (Orgs.). O livro da saúde das mulheres negras: nossos passos vêm 
de longe. 2. ed. Rio de Janeiro: Pallas: Griola: Global Exchange, 2006. p. $42-6 \mathrm{I}$.

BENTO, M. A. S. Pactos narcísicos no racismo: branquitude e poder nas organizações empresariais e no poder público. 2002. Tese (Doutorado em Psicologia) - Instituto de Psicologia, Universidade de São Paulo, São Paulo, 2002.

CARDOSO, G. P. Amefricanizando o feminismo: o pensamento de Lélia Gonzalez. Estudos Feministas, Florianópolis, v. 22, n. 3, p. 965-986, set. 2014.

CARNEIRO, F. Nossos passos vêm de longe. In: WERNEGK, J.; MENDONÇA, M.; WHITE, E. (Orgs.). O livro da saúde das mulheres negras: nossos passos vêm de longe. 2. ed. Rio de Janeiro: Pallas: Griola: Global Exchange, 2006. p. $22-4 \mathrm{I}$.

COLLINS, P. H. Black feminist thought: Knowledge, consciousness, and the politics of empowerment. New York: London: Routledge, 2000.

FREYRE, G. Casa-grande \& senzala: formação da família brasileira sob o regime da economia patriarcal. 50. ed. São Paulo: Global, 2005.

GONZALEZ, L. Racismo e sexismo na cultura brasileira. Ciências Sociais Hoje, Brasília, n. 2, p. 223-244, I984.

A categoria político-cultural de amefricanidade. Tempo Brasileiro, Rio de Janeiro, n. 92/93, p. 69-82, jan./jun. I988.

MARCONDES, M. M. et al. (Orgs.). Dossiê mulheres negras: retrato das condições de vida das mulheres negras. Brasília: Ipea, 20I3. Disponível em: <https://bit. ly/2KDcnoq>. Acesso em: 8 ago. 2018.

FERREIRA, A. B. de. H. Novo Dicionário Aurélio da Língua Portuguesa. 4. ed. Guritiba: Positivo, 2009. p. I368.

TEIXEIRA, P. A. S.; PINTO, A. S.; MORAES, O. G. R. (Orgs.). Dossiê Mulher 2010. Rio de Janeiro: Riosegurança: Instituto de Segurança Pública, 2010. Disponível em: 〈https://bit.ly/2OlslhE〉. Acesso em: 8 ago. 2018.

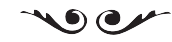

Marina de Oliveira Reis é graduada em Direito pela Pontifícia universidade Católica do Rio de Janeiro.

marina_reisI2@hotmail.com 